\title{
RUDISTS: BIVALVE MORPHOSPACE ABANDONED AND RE-ENTERED
}

SEILACHER, Adolf, Dept. of Geology, Yale University, P.0.Box: 208109 New Haven, CT, 06520, USA and Geolog. Institut der Universität, 72076 Tübingen, Germany

As shown by computer and candle wax simulation, hinged bivalvedness confines accretionary shells to a high-expansion subset of spiral cones. In our view, rudists are derived form a cemented stock that lost its ligament and replaced it by diductor muscles. This allowed them to evolve coralliform shells with a conical attached valve and a lid-like free valve, as useful for sediment stickers. The second key innovation was the development of mantle diverticles, which

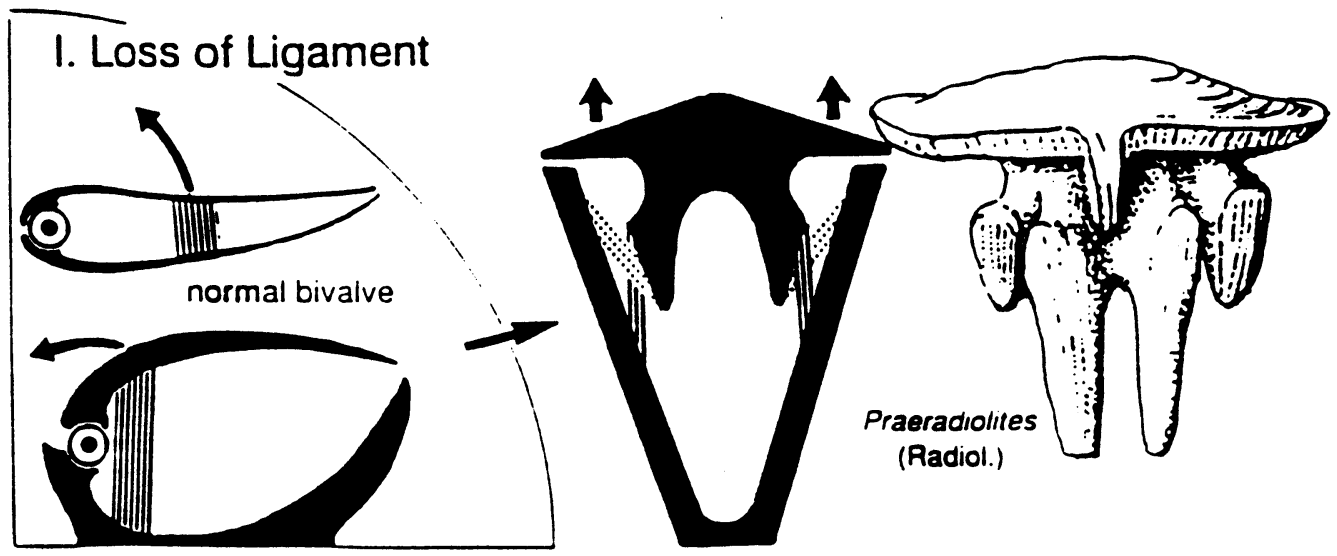

II. Pallial Diverticles

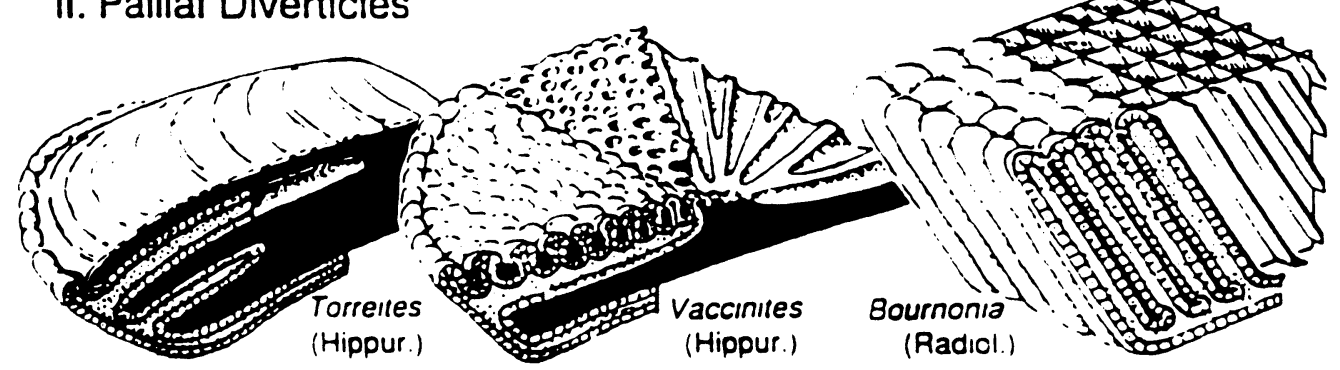

primarily served for the fabrication of light-weight shells (needed by iceberg strategists), but at the same time lent themselves for algal gardens in photosymbiotic species. Photosymbiosis also lured some forms back to the sediment surface, where one or both valves became flattened for stable reclining (Biradiolites, Bournonia, Titanosarcolites). In some sediment stickers (Biradiolites, Torreites), commissural folding on one flank re-established $a$ kind of swing-door opening. As a consequence, the iid valve (not the attached one) returned to the bivalvian morphospace -- but with the umbo now on the opposite side of the original ligament position.

This example illustrates the usefulness of the morphospace concept, as long as a clear distinction is made between functional and fabricaticnal morphospaces. 